\title{
Expression of Tyrosine Hydroxylase in Neurons of Cultured Cerebral Cortex: Evidence for Phenotypic Plasticity in Neurons of the CNS
}

\author{
L. lacovitti, J. Lee, T. H. Joh, and D. J. Reis \\ Department of Neurology, Laboratory of Neurobiology, Cornell University Medical College, New York, New York 10021
}

In vivo, neurons of the cerebral cortex of rat embryos did not stain with antibodies to the catecholamine (CA) biosynthetic enzyme tyrosine hydroxylase (TH) even when examined using a highly sensitive technique for radioimmunocytochemistry. However, when embryonic day (E) 13 cortex was grown $1 \mathrm{~d}$ in culture, several thousand cells expressed immunoreactive and catalytically active TH. All TH cells simultaneously labeled with the neuronal enzyme, neuronal specific enolase, indicating that the TH was excusively localized in neurons. Moreover, all TH neurons were postmitotic since they did not incorporate ${ }^{3} \mathrm{H}$-thymidine. With time in culture, the number of TH cells selectively declined from nearly 3000 cells at 2 d to several cells at $14 \mathrm{~d}$. Similarly, the number of neurons competent to express $\mathrm{TH}$ in culture declined with advancing age of the donor embryo. Thus, by E18, very few cortical neurons had the capacity to express TH.

We conclude that during a critical period of development, postmitotic cerebral cortical neurons can express catecholamine traits in vitro but not in vivo. Thus, the neurotransmitter phenotype of certain classes of central neurons is not fixed but can be influenced by epigenetic factors found in their environment, thereby providing evidence of phenotyic plasticity in the central nervous system (CNS).

It is now well established that the neurotransmitter phenotype of neurons of the peripheral nervous system (PNS), once held to be immutable, is in fact extremely plastic. For example, the biochemical differentiation of cells of the neural crest into adrenergic neurons of sympathetic ganglia or cholinergic parasympathetic neurons depends greatly on factors encountered in the environment during and after their embryonic migration (LeDouarin, 1980). Moreover, these factors continue to modulate phenotypic expression even after neural crest cells have withdrawn from the mitotic cycle and expressed differentiated properties (Landis and Keefe, 1973; Bunge et al., 1978; Patterson, 1978). Thus, under appropriate conditions, fully differentiated sympathetic neurons can express cholinergic traits (Bunge et al., 1978; Patterson, 1978) and, conversely, parasympathetic neurons can express adrenergic traits (Landis et al., 1983; Iacovitti et al., 1985a; Teitelman et al., 1985).

\footnotetext{
Received May 12, 1986; revised Aug. 6, 1986; accepted Aug. 11, 1986.

This research was supported by NIH Grant 18974 and NSF Grant DCB 8303019.

Correspondence should be addressed to Dr. L. Iacovitti, Department of Neurology, Laboratory of Neurobiology, Cornell University Medical College, $411 \mathrm{E}$. 69th St., New York, NY 10021

Copyright (C) 1987 Society for Neuroscience $0270-6474 / 87 / 041264-07 \$ 02.00 / 0$
}

It is not known whether neurons in the central nervous system (CNS) share comparable degrees of biochemical plasticity. That they may was suggested by a recent study in the retina (Schnitzer and Rusoff, 1984) as well as by our own observation that if the cerebral cortex of embryonal rats was dissociated, grown in culture and stained with antibodies to the catecholamine (CA) biosynthetic enzyme tyrosine hydroxylase (TH), many cells in the culture contained the enzyme (Iacovitti et al., 1985b). The observation was unexpected since it is well established that in the adult neurons which synthesize, store, and release CAs are not contained within the cerebral cortex but rather reside within specific nuclei of the brain stem (Ungerstedt, 1971). The unexpected appearance of TII in cells which do not normally contain it raises the possibility that the neurons of the cerebral cortex may be infuenced by epigenetic factors present in their environment.

In the present study we therefore sought to determine whether the expression of the TH phenotype in cells of the embryonal cerebral cortex is restricted to neurons, whether such neurons have completed their cell replication, whether the expression of the enzyme is transient or permanent, and whether it is influenced by the age at which the cells are removed from the developing rat. We shall demonstrate, immunocytochemically and biochemically, that postmitotic neurons of the cerebral cortex can express the CA enzyme $\mathrm{TH}$ in culture but not in vivo.

\section{Materials and Methods}

\section{Tissue culture}

Pregnant Sprague-Dawley rats were purchased from Hilltop Lab Animals (Scottsdale, $\mathrm{Pa}$.) at $12 \mathrm{~d}$ gestation $\pm 12 \mathrm{hr}$ fertilization day $=$ embryonic day (E) 0 . On E13,14, 16, or 18, rats were anesthetized with pentobarbital, and the embryos removed. After dissection of the brain from the cranium, the cerebral cortices, excluding the anterior poles, were isolated. After the removal of the meninges, the cortical tissue was incubated in $\mathrm{Ca}^{2+}, \mathrm{Mg}^{2+}$-free Hank's balanced salt solution (CMFHBSS) for $10 \mathrm{~min}$ at $37^{\circ} \mathrm{C}$ in a clinical rotator (minimum setting). The incubation mixture was replaced with a $0.01 \%$ trypsin solution (in CMFHBSS), and cortices incubated for another $10 \mathrm{~min}$, rinsed twice in Leibovitz medium $(\mathrm{L}-15)$, and placed in culture medium containing Dulbecco's minimum essential medium, 10\% fetal calf serum (Irvine Scientific) glucose $(6 \mathrm{mg} / \mathrm{ml})$, glutamine $(204 \mu \mathrm{g} / \mathrm{ml})$, and penicillin/ streptomycin $(100 \mathrm{U} / \mathrm{ml})$. The cells were dissociated by trituration through a reduced bore borosilicate glass pipette. The cell suspension was filtered through a sterile 15- $\mu \mathrm{m}$ Nitex filter and plated onto plastic (Aclar) culture dishes coated either with polymerized collagen or with polyornithine (precoated for $4 \mathrm{hr}$ at room temperature at a concentration of $1.0 \mathrm{mg}$ ) $\mathrm{ml}$ in $15 \mathrm{~mm}$ borate buffer, $\mathrm{pH} 8.4$ ). The cellular plating density corresponded to 2 cortices/dish (approximately $5 \times 10^{5}$ cells/dish). Cortical cells formed fewer cell aggregates on polyornithine than on collagen; hence, in radioautography experiments, which required that all cells be evenly coated with emulsion, cells were grown on polyornithine. In all other experimental manipulations, both substrata were used. 

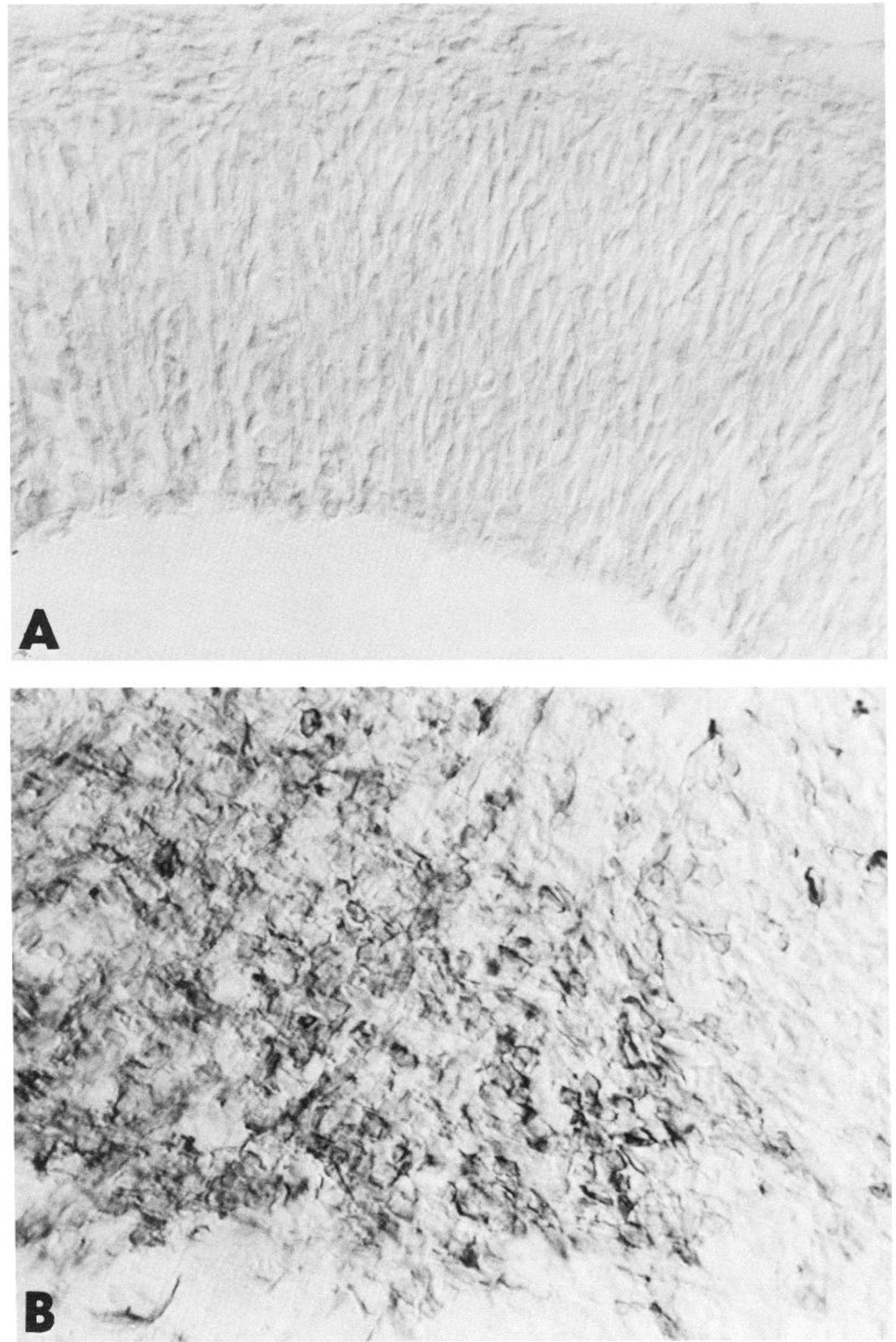

Figure 1. Immunocytochemical localization of TH in cross sections of E14 rat brain. Note absence of TH labeling in cortical cells $(A)$ even though CA cell bodies and processes are darkly stained in brain-stem nuclei $(B)$.

\section{Immunocytochemistry}

Single label experiments. Rat embryos were removed at E13, 14, 16, and 18 , and immersed in fixative solution ( $4 \%$ formaldehyde generated from paraformaldehyde in $0.1 \mathrm{~m}$ sodium phosphate buffer, $\mathrm{pH} 7.2$ ). The brains were removed, fixed for $1 \mathrm{hr}$, washed twice with $0.1 \mathrm{M}$ phosphate buffer, embedded in a $30 \%$ sucrose solution overnight, and serially sectioned at $16 \mu \mathrm{m}$ in a cryostat microtome. The sections were thawmounted onto glass slides precoated with a $1 \%$ gelatin solution.

Immunohistochemical staining was carried out using either the soluble peroxidase-antiperoxidase (PAP) method of Sternberger (1974) as described by Teitelman et al. (1978), or the highly sensitive ${ }^{125}$ I-labeling 
Figure 2. Immunocytochemical localization of $\mathrm{TH}$ in E14 rat cortex maintained $2 \mathrm{~d}$ in vitro $(A)$. Note the beaded varicose processes elaborated by stained neurons $(B$, arrow).
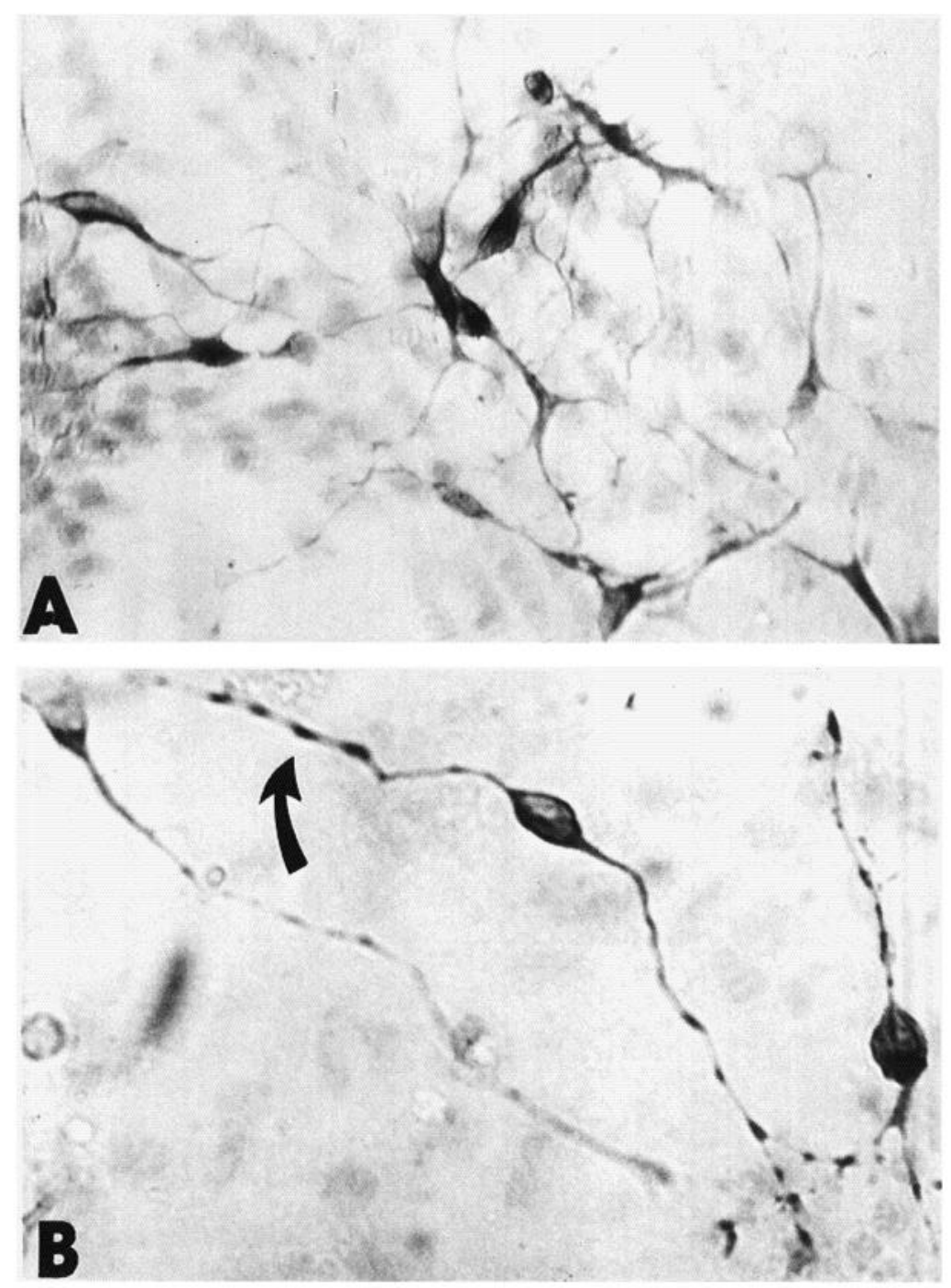

technique described in the following section. The procedures for preparation of antibodies to TH and DBH and the criteria for establishing their specificity are described elsewhere (Joh and Ross, 1983; Teitelman et al., 1985). Antibodies were determined to be specific by their ability to precipitate enzyme activity from a crude tissue homogenate, by the production of a single immunoprecipitin arc when analyzed by immunodiffusion and immunoelectrophoresis against a crude antigen preparation, and by the highly sensitive technique of Western blotting. Antibodies to neuronal specific enolase (NSE) were purchased from Polysciences, Inc.

In experiments designed to study $\mathrm{TH}$ expression in cortical neurons in vitro, cultures incubated $1,3,5,8,10$, and $14 \mathrm{~d}$ were rinsed extensively in Hank's balanced salt solution and then fixed for $60 \mathrm{~min}$ in the formaldehyde solution described above. Following fixation, cultures were stained by the PAP method as described by Iacovitti et al. (1981).

Double labeling. The procedure for labeling 2 antigens simultaneously (double label) have been described elsewhere (Pickel et al., 1986). Briefly, cultures were first incubated overnight with antibodies against TH (diluted $1: 30,000)$. Such a high dilution of antibody was chosen in order to avoid nonspecific labeling of $\mathrm{TH}$ cells with the DAB used to localize the second antigen, NSE. Cultures were next incubated for $45 \mathrm{~min}$ with a 1 to 50 dilution [Tris buffered saline (TBS) $+1 \%$ goat serum] of a solution of donkey-antirabbit IgG labeled with ${ }^{125}$ I (specific activity, 5$20 \mu \mathrm{Ci} / \mu \mathrm{g}$; Amersham). The following day the cultures were rinsed 6 times in TBS and exposed for $24 \mathrm{hr}$ to a 1:500 dilution of antibodies against NSE. Finally the cultures were sequentially incubated with a 1:50 dilution of goat antirabbit $\mathrm{IgG}$ for $30 \mathrm{~min}$ and to a 1:100 dilution of PAP. The bound PAP complex was visualized by incubating the cultures with $0.013 \% \mathrm{DAB}$ and $0.01 \%$ of hydrogen peroxide. After the
$\mathrm{DAB}$ reaction the cultures were air-dried overnight and dipped in Ilford L-4 photographic emulsion, air-dried and incubated in a light-tight box containing a drying agent (Drierite) at $4^{\circ} \mathrm{C}$. After 1 week the cultures were developed for $3 \mathrm{~min}$ at $16-17^{\circ} \mathrm{C}$ in Kodak D-19 developer, rinsed in water, fixed in Kodak Ektaflo (diluted 1:3) for $8 \mathrm{~min}$ at $4^{\circ} \mathrm{C}$, dehydrated and mounted in Permount.

\section{Thymidine labeling}

To determine whether cells in culture synthesize DNA, cortical cells were plated as described and after $1 \mathrm{hr}$ media containing $0.05 \mu \mathrm{C}_{\mathrm{r}} / \mathrm{ml}$ of ${ }^{3} \mathrm{H}$-thymidine (specific activity, $78.0 \mathrm{C}_{\mathrm{i}} / \mathrm{mmol}$ ) was added. After $1 \mathrm{~d}$ in vitro, cultures were fixed with $4 \%$ formaldehyde and processed for the immunohistochemical visualization of $\mathrm{TH}$ as well as the autoradiographic localization of incorporated thymidine. This double-labeling technique has been described previously (Teitelman et al., 1985). Thymidine-labeled cells were identified by the presence of silver grains over the nucleus.

\section{TH assay}

For biochemical determination of TH enzyme activity, cortical cultures were processed as described elsewhere (Iacovitti et al., 1981). Sister cultures were simultaneously stained with antibodies to $\mathrm{TH}$ and positively labeled cells were counted. It was estimated from cell counts that biochemical samples each contained approximately 20,000 TH cells. As controls for the assay, the adult rat substantia nigra, an area rich in TH neurons, was simultaneously homogenized and assayed using a modification of the method of Coyle (1972). All samples were run in duplicate 


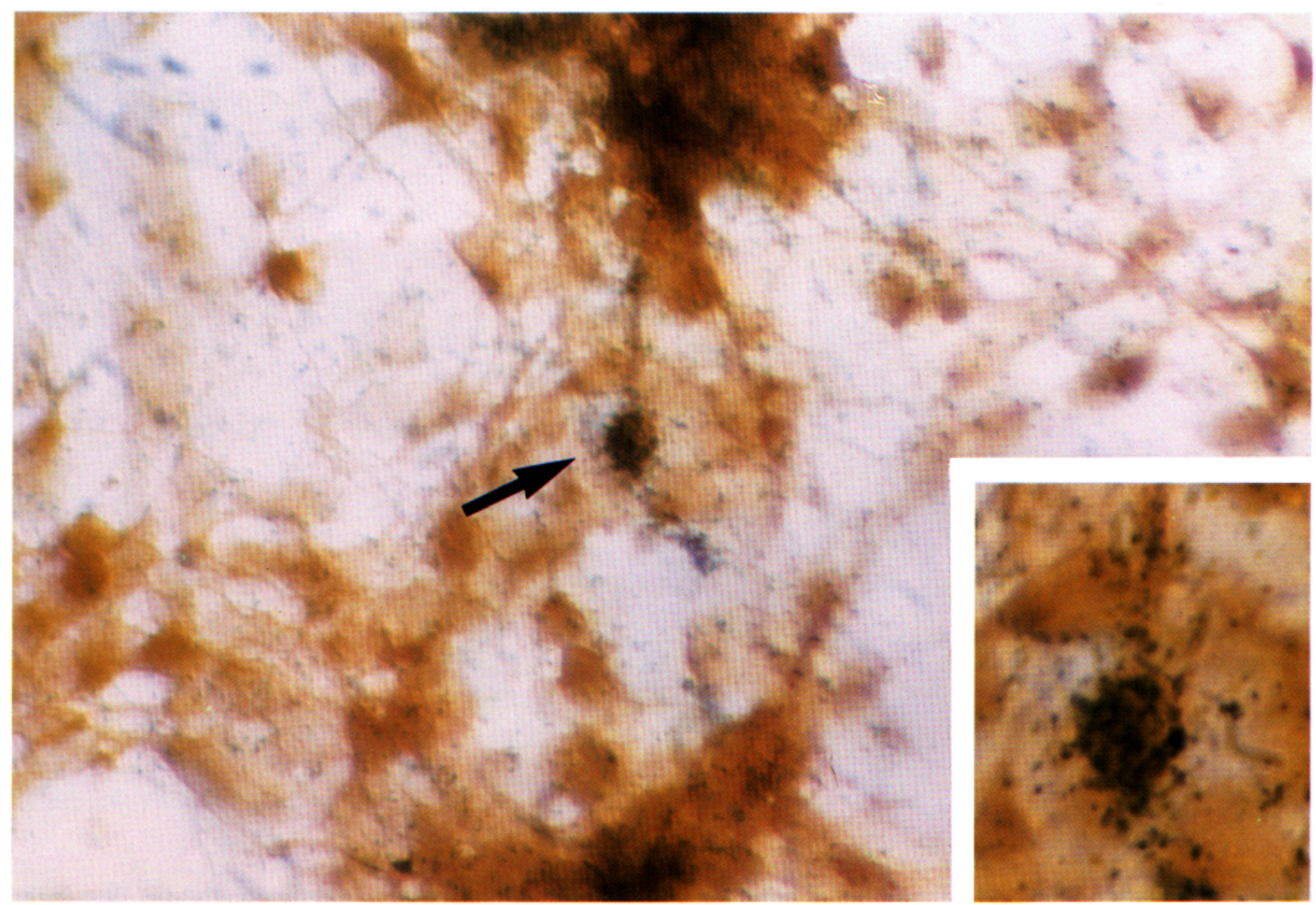

Figure 3. Cultures of E14 cortex maintained $2 \mathrm{~d}$ in vitro and sequentially stained with TH, visualized by radioautography, and NSE, visualized by the peroxidase-antiperoxidase technique. Note the presence of neurons which label only for NSE, seen as the brown precipitate of diaminobenzidine. Other cells, indicated by arrow, contain both TH and NSE since they label both with silver grains and diaminobenzidine (see inset).

in the presence and absence of the tyrosine substrate inhibitor, 3-iodotyrosine $\left(2 \times 10^{-4} \mathrm{M}\right)$. Samples were pre-incubated for $5 \mathrm{~min}$ at $30^{\circ} \mathrm{C}$ with or without inhibitor before tyrosine was added to the assay mixture.

\section{Results}

\section{TH in cerebral cortical neurons in vivo}

Brains were removed from fetal rats on days E13, 14, or 16, serially sectioned, and processed for the immunocytochemical localization of TH using either the PAP method or the highly sensitive ${ }^{125}$ I-labeling technique.

TH-immunoreactive cells were not seen in the cerebral cortex (Fig. 1A). However, neurons of the developing substantia nigra were intensely labeled (Fig. $1 B$ ), demonstrating that the absence of staining in cortex could not be attributed to a failure of the antibody to stain embryonic tissue. These findings, in agreement with others (Specht et al., 1981), indicate that in the midgestational embryo, as in the adult (Ungerstedt, 1971), neurons of the cerebral cortex do not contain detectable levels of immunoreactive $\mathrm{TH}$.

\section{Appearance of $\mathrm{TH}$ in neurons in vitro}

In contrast to the situation in vivo, cultures of cerebral cortex obtained from rats on E13-14 contained a large population of cells which stained with antibodies to TH (Fig. $2 A$ ). Staining of cortical cells with $\mathrm{TH}$ was observed as early as $1 \mathrm{~d}$ in vitro. No cells stained with antibodies to DBH.

To further establish whether TH was expressed in neurons, cultures were processed for the simultaneous localization of $\mathrm{TH}$ and the neuronal marker, neuronal specific enolase (NSE). All TH-immunoreactive cortical cells also contained NSE (Fig. 3), indicating that $\mathrm{TH}$ was expressed exclusively in neurons of the cerebral cortex and not in glia nor endothelium. Since those cells that labeled both with TH and NSE represented only a small fraction of the NSE-labeled cells in culture, TH expression was restricted to a particular subclass of cortical neurons. The neurons within this subclass, however, were morphologically heterogeneous; labeled neurons were stellate, bipolar, and pyramidal in shape. Many TH cells elaborated varicose processes (Fig. 2B).

\section{Enzymatic activity of TH in cortical cultures}

To determine if immunoreactive TH reflected the presence of catalytically active enzyme, TH activity was measured in cultures grown $2 \mathrm{~d}$ in vitro. Sister cultures were simultaneously

Table 1. TH activity levels in cerebral cortex grown $2 \mathrm{~d}$ in vitro

\begin{tabular}{lcr} 
Tissue & 3-Iodotyrosine & \\
pretreatment & CPM \\
\hline Buffer blank & - & 402 \\
Buffer blank & + & 413 \\
Cultures of cerebral cortex & - & 669 \\
Cultures of cerebral cortex & + & 356 \\
Substantia nigra & - & 29,936 \\
Substantia nigra & + & 437
\end{tabular}

In a typical experiment, 2-day old cultures of E14 cerebral cortex were pooled into samples, each containing approximately $20,000 \mathrm{TH}$ immunoreactive neurons. Cultures were homogenized and assayed in the presence and absence of the competitive inhibitor, 3-iodotyrosine $\left(2 \times 10^{-4} \mathrm{M}\right)$. As controls, homogenates of adult rat substantia nigra were assayed simultaneously. 
Figure 4. Combined radioautography and immunocytochemistry in cultures of $\mathrm{E} 14$ cortex grown $1 \mathrm{~d}$ in vitro in the presence of ${ }^{3} \mathrm{H}$-thymidine. Note that cells containing $\mathrm{TH}$ immunoreactivity do not have silver grains over their nuclei (arrow).

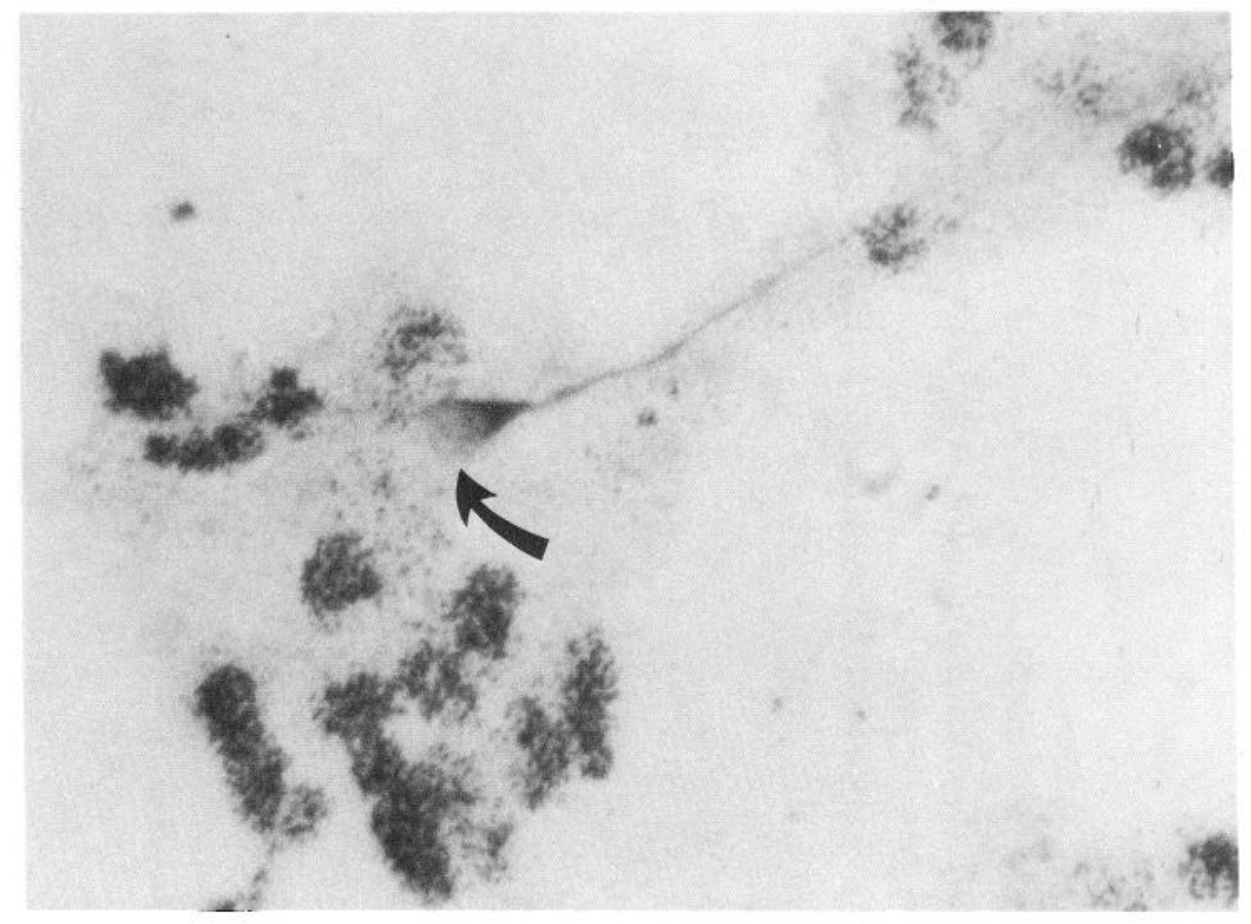

processed for immunocytochemistry and the number of neurons containing TH were counted.

In 3 separate experiments, 2-d-old cultures were pooled into samples each containing approximately 20,000 TH-positive neurons and were radioenzymatically assayed in the presence and in the absence of the competitive substrate inhibitor 3iodotyrosine (Table 1). In all experiments, counts derived from cortical cultures were extremely low, never reaching levels greater than $400 \mathrm{cpm}$ above blank. However, since even these low values were reduced to blank level by preincubating cortical homogenates with 3-iodotyrosine, they probably represent very low levels of TH catalytic activity. For comparison, homogenates of adult rat substantia nigra were simultaneously assayed. TH activity, which is very high in nigra, was also effectively eliminated when assayed in the presence of 3-iodotyrosine.

\section{Relationship of expression of TH to cell cycle}

The majority of cells in the rat cerebral cortex actively divide at E13 (Raedler and Sievers, 1976; Raedler and Raedler, 1978). To establish whether the cortical neurons expressing TH are still mitotic, cortices removed from rats at $\mathrm{E} 13$ were grown in media containing ${ }^{3} \mathrm{H}$-thymidine. After $1 \mathrm{~d}$, cultures were fixed and processed for the immunocytochemical localization of $\mathrm{TH}$ and radioautography.

$\begin{aligned} & \text { Table 2. Decline in number of TH immunoreactive cortical cells with } \\
& \text { time in culture }\end{aligned}$
\begin{tabular}{lc} 
Days in vitro & Number of $\mathrm{TH}$ cells/culture \\
\hline 2 & $2717 \pm 841$ \\
8 & $893 \pm 189$ \\
14 & $21 \pm 8$
\end{tabular}

Each number represents the mean $\pm \mathrm{SE}$ of 4 cultures from 2 different experimental platings.
TH-immunoreactive cortical cells did not incorporate ${ }^{3} \mathrm{H}$ thymidine into their nuclei (Fig. 4). In contrast, silver grains were seen over the nuclei of the majority of cells lacking $\mathrm{TH}$ (Fig. 4), indicating that they had replicated while in culture. Thus, at E13, the neurons expressing TH in the cerebral cortex no longer divide.

\section{Effects of time in culture on expression of $T H$}

To assess whether the duration of time in culture influenced the phenotypic expression of TH in cortical neurons, cortices were removed from rat embryos at E13, plated and examined 2, 8, and $14 \mathrm{~d}$ later.

Despite the fact that the total number of neurons in the dish did not appear to decline with time in culture, the number of neurons expressing $\mathrm{TH}$ decreased dramatically (Table 2 ). Thus, at $2 \mathrm{~d}$ there were nearly $3000 \mathrm{TH}$ neurons, at $8 \mathrm{~d}$, fewer than a thousand TH neurons, and by $14 \mathrm{~d}$, very few TH neurons were present, indicating a loss either in TH expression or cell viability with time in culture.

\section{Effect of age of donor on expression of TH in cortical cultures}

To establish whether the capacity of neurons to express TH was related to the embryonic age of the tissue, cerebral cortices were

\begin{tabular}{|c|c|}
\hline $\begin{array}{l}\text { In vivo age at time } \\
\text { of explanation } \\
\text { (E) }\end{array}$ & $\begin{array}{l}\text { Number of TH cells/culture } \\
\text { at } 2 \mathrm{~d} \text { in vitro }\end{array}$ \\
\hline $13-14$ & $2444 \pm 636$ \\
\hline 16 & $339 \pm 121$ \\
\hline 18 & $21 \pm 4$ \\
\hline
\end{tabular}

Each number represents the mean $\pm \mathrm{SE}$ of 4 cultures from 2 different experimental platings. 
removed from rats at E13, 16, and 18, plated and examined 2 $\mathrm{d}$ later. As seen in Table 3, the number of TH-immunoreactive neurons dramatically declined as the age of the donor embryo increased. Thus, cortical cultures derived from embryos at E1314 contained several thousand TH-positive neurons, those from embryos at E16 several hundred, and those from embryos at E18 contained only a rare $\mathrm{TH}$-immunoreactive cell. These results suggest that either cortical neurons have the capacity to express TH in culture only during a critical period in their development, or that mature cortex contains a substance(s) which inhibits the expression of $\mathrm{TH}$.

To assess whether the cortex at E18 contained a substance(s) which might inhibit the expression of $\mathrm{TH}$ in the cortex of a younger animal, co-cultures were established consisting of cortical cells obtained from both young and old embryos. Cells from E18 rat cortex were dissociated and plated simultaneously with E14 cortical cells. Sister cultures from either E14 embryos or from E1 8 embryos were grown as controls. While in culture, it was not possible to distinguish between cells of different ages, co-cultures examined 2 and $8 \mathrm{~d}$ after plating showed no loss of TH neurons (Table 4) as compared with cultures containing only E14 cortical cells. This indicates that contact with or substances released by the mature cortex did not prevent the expression of TH in younger tissues and, therefore, cannot explain the failure of more mature cortical neurons to express $\mathrm{TH}$. Quite to the contrary, there was a 2 -fold increase in the number of TH-containing neurons in co-cultures of E14 and 18 cortex (Table 4), suggesting that factors present in co-culture promote an increase either in the number of cells expressing $\mathrm{TH}$ or in the viability of $\mathrm{TH}$ cells in vitro.

\section{Discussion}

We have found, in agreement with others (Specht et al., 1981), that the cerebral cortex of the embryonic rat is devoid of perikarya containing the CA biosynthetic enzyme TH. Yet if the cortex is removed from the embryo, dissociated and grown in culture, many of its cells express the enzyme. These TH-positive cells are neurons since they all contain the specific neuronal marker NSE. Moreover, the neurons which express TH do not synthesize DNA and are, therefore, postmitotic. The enzyme present in these neurons is both immunoreactive and catalytically active. The fact that DBH is not detected in cultures suggests that the neurons may have the capacity to synthesize dopamine but not other CA neurotransmitters. Whether or not these neurons synthesize, store, and/or release CAs is not known.

The appearance of a heretofore unexpressed neurotransmitter trait in postmitotic cortical neurons indicates that the neurotransmitter phenotype of these cells is not predetermined during development but can be epigenetically regulated. In the PNS, the environment is known to play a critical role in specifying neurotransmitter type (Bunge et al., 1978; Patterson, 1978; LeDouarin, 1980; Landis and Keefe, 1983; Iacovitti et al., 1985a; Tcitclman et al., 1985). Our finding in cortcx indicates that the same principles which govern neurotransmitter choice in peripheral neurons may also apply to certain classes of central neurons.

However, in contrast with the PNS where neurotransmitter phenotype remains labile for several weeks after cells have withdrawn from the cell cycle (Bunge et al., 1978; Patterson, 1978; Iacovitti et al., 1985a; Teitelman et al., 1985); in the cerebral cortex, the developmental window for phenotypic plasticity is much narrower. Thus, at E13, many cortical cells have the ca-
Table 4. Co-culture of E14 and E18 cortex increases the number of TH immunoreactive cortical cells

\begin{tabular}{lcc} 
& \multicolumn{2}{l}{ Number of TH cells } \\
\cline { 2 - 3 } Cortex & $2 \mathrm{~d}$ in vitro & $8 \mathrm{~d}$ in vitro \\
\hline E14 & $2335 \pm 119$ & $622 \pm 239$ \\
E18 & $11 \pm 7$ & 0 \\
E14 + E18 & $5016 \pm 903$ & $1385 \pm 149$
\end{tabular}

Each number represents the mean \pm SE of 6 cultures from 2 separate experimental platings.

pacity to express $\mathrm{TH}$ in culture, but by E18 only an occasional TH competent cell remains. It is unlikely that the loss of this capacity reflects the presence of a substance(s) in maturing cortex which inhibit TH expression since the ability of E14 cortical cells to express $\mathrm{TH}$ is not only maintained when co-cultured with E1 8 cortex, but is substantially increased. Rather, it seems more likely that there is a critical period during embryogenesis of the cortex when neurons are competent to express a novel enzyme, such as TH, after which time their phenotype becomes fixed.

Even in those cortical neurons which are competent to express $\mathrm{TH}$ in culture, the expression of the enzyme appears to be shortlived. Thus, the number of TH-positive neurons gradually declines with time in culture. It is conceivable that the factors which signal TH expression differ from those that maintain it, with the latter decreasing over time in vitro. Indeed, the transient expression of neurotransmitter synthetic enzymes has been described in a number of neural (Cochard et al., 1978; Teitelman et al., 1978, 1981a; Jonakait et al., 1979, 1984; Schnitzer and Rusoff, 1984; Berger et al., 1985) and non-neural (Teitelman et al., 1981b, c) tissues. For example, islet cells of the pancreas contain TH only transiently before transformaton into cells of another phenotypic characterization (Teitelman et al., 1981b, c). Cortical cells, in a similar fashion, may forfeit their expression of TH as they acquire traits of yet another neurotransmitter system. Alternatively, the disappearance of $\mathrm{TH}$ positive cortical neurons may result from the death of these cells over time in culture.

The fact that $\mathrm{TH}$ is seen in cortical neurons in vitro but not in vivo indicates that the environment provided in culture facilitates this expression. The source of these environmental signals, however, remains unknown. It is unlikely that serum factors are involved in the signaling process even though fetal calf serum is present in these experiments, since cultures established in a serum-free defined medium continue to contain abundant TH immunoreactive cells (unpublished observations). Alternatively, it is possible that CA differentiation is promoted in cortical neurons as a result of differences in the cellular microenvironment in vivo and in vitro. However, this too seems an unlikely explanation in light of the fact that when normal histiotypic relationships are maintained in a cortical transplant, cclls still cxpress TH (Smith et al., 1985). Taken together, these findings raise the possibility that environmental factors do not directly activate expression of the TH gene. Rather, it is possible that certain classes of cortical neurons have the intrinsic ability to express $\mathrm{TH}$ in vivo and may even do so at low but undetectable levels. Such potentiality for TH expression, however, is transient and may be held in check by intrinsic inhibitory molecules, possibly originating from target structures in vivo. According to this proposition, when cortical cells are explanted to culture before receiving this inhibitory influence (E14) they are able to 
express the enzyme. At later times in development, after cells innervate target structures, their phenotypic potentiality becomes restricted.

We are not at all certain which neurons in the mature cortex correspond to those capable of expressing $\mathrm{TH}$ in the embryo. However, since the TH-containing neurons withdraw from the cell cycle before day 13 of gestation, in advance of the majority of developing cortical cells (Duckett and Pearse, 1968; Raedler and Sievers, 1976; Konig et al., 1977; Raedler and Raedler, 1978), the most interesting possibility is a group of neurons first discovered by Ramon y Cajal (1891) and later described by Retzius (1893). These so-called Cajal-Retzius cells are the first neurons generated in the mammalian cortex, beginning on E1 1 (Duckett and Pearse, 1968; Raedler and Sievers, 1976; Konig et al., 1977; Raedler and Raedler, 1978). In addition to the timing of their terminal mitosis, these cells are morphologically heterogeneous (Raedler and Raedler, 1978), similar to the THcontaining cortical neurons. Taken together, these findings raise the possibility that the cortical neurons which are competent to express TH may comprise at least a subpopulation of CajalRetzius cells in the cortex. Alternatively, these neurons may correspond to a recently described population of perikarya that transiently express TH from postnatal days 14 to 30 in the rat neocortex (Berger et al., 1985), or to some as yet undefined population of cells.

\section{References}

Berger, B., C. Verney, P. Gaspar, and A. Febvret (1985) Transient expression of tyrosine hydroxylase immunoreactivity in some neurons of the rat neocortex during postnatal development. Dev. Br. Res. 23: 141-144.

Bunge, R. P., M. Johnson, and C. D. Ross (1978) Nature and nurture in the development of the autonomic neuron. Science 199: 14091416 .

Cochard, P., M. Goldstein, and I. B. Black (1978) Ontogenetic appearance and disappearance of tyrosine hydroxylase and catecholamines in the rat embryo. Proc. Natl. Acad. Sci. USA 75: 2986-2990.

Coyle, J. T. (1972) Tyrosine hydroxylase in rat brain-cofactor requirements, regional and subcellular distribution. Biochem. Pharmacol. 21: $1935-1944$.

Duckett, S., and G. E. Pearse (1968) The cells of Cajal-Retzius in the developing human brain. J. Anat. 102: 183-187.

Iacovitti, L., T. H. Joh, D. H. Park, and R. P. Bunge (1981) Dual expression of neurotransmitter synthesis in cultured autonomic neurons. J. Neurosci. 1: 685-690.

Iacovitti, L., T. H. Joh, V. R. Albert, D. H. Park, D. J. Reis, and G. Teitelman (1985a) Partial expression of catecholaminergic traits in cholinergic chick ciliary ganglia: Studies in vivo and in vitro. Dev. Biol. 110: 402-412.

Iacovitti, L., J. Lee, T. H. Joh, and D. J. Reis (1985b) Embryonic rat cerebral cortical cells express tyrosine hydroxylase in tissue culture. Soc. Neurosci. Abstr. 11: 667.

Joh, T. H., and M. E. Ross (1983) Preparation of catecholaminesynthesizing enzymes as immunogens for immunohistochemistry. In Immunohistochemistry, A. C. Cuello, ed., pp. 121-138, Wiley, Chichester, U.K.

Jonakait, G. M., J. Wolff, P. Cochard, M. Goldstein, and I. B. Black
(1979) Selective loss of noradrenergic phenotypic characters in neuroblasts of rat embryo. Proc. Natl. Acad. Sci. USA 76: 4683-4686.

Jonakait, G. M., K. A. Markey, M. Goldstein, and I. B. Black (1984) Transient expression of selected catecholaminergic traits in cranial sensory and dorsal root ganglia of embryonic rat. Dev. Biol. 101: 5160 .

Konig, N., J. Valat, J. Fulcrand, and R. Marty (1977) Identification of Cajal-Retzius cells in immature rodent cerebral cortex: A combined Golgi-EM study. Neurosci. Lett. 4: 21-26.

Landis, S. C., and D. Keefe (1983) Evidence for neurotransmitter plasticity in vivo: Developmental changes in properties of cholinergic sympathetic neurons. Dev. Biol. 98: 349-372.

Landis, S. C., P. C. Jackson, J. R. Fredieu (1983) Catecholaminergic properties of neurons and preganglionic axons in the rat ciliary ganglion. Soc. Neurosci. Abstr. 9: 937.

LeDouarin, N. M. (1980) The Neural Crest, Cambridge U. P., London, U.K.

Patterson, P. H. (1978) Environmental determination of autonomic neurotransmitter functions. Annu. Rev. Neurosci. $1: 1-17$.

Pickel, V. M., J. Chan, and T. A. Milner (1986) Autoradiographic detection of ${ }^{125} \mathrm{I}$-secondary antiserum: A sensitive light and electron microscopic labeling method compatible with peroxidase immunocytochemistry for dual localization of neuronal antigens. J. Histochem. Cytochem. 34: 707-718.

Raedler, E., and A. Raedler (1978) Autoradiographic study of early neurogenesis in rat neocortex. Anat. Embryol. 154: 267-284.

Raedler, A., and J. Sievers (1976) Light and electron microscopical studies on specific cells of the marginal zone in the developing rat cerebral cortex. Anat. Embryol. 149: 173-181.

Ramon y Cajal, S. (1891) Sur la structure de l'ecorce cerebrale de quelques mammiferes. Cellule 7: 125-176.

Retzius, G. (1893) Die Cajal'schen zellen des grosshirnrinde beim menschen and bei saugetieren. Biol. Untersuch. 5: 1-9.

Schnitzer, J., and A. C. Rusoff (1984) Horizontal cells of the mouse retina contain glutamic acid decarboxylase-like immunoreactivity during early developmental stages. J. Neurosci. 4: 2948-2955.

Smith, L. M., T. H. Joh, and F. F. Ebner (1985) The expression of catccholaminc cnzymes by ncocortical ncurons. Soc. Ncurosci. Abstr. 11: 667 .

Specht, L. A., V. M. Pickel, T. H. Joh, and D. J. Reis (1981) Light microscopic immunocytochemical localization of tyrosine hydroxylase in prenatal rat brain. 1. Early ontogeny. J. Comp. Neurol. 199; 233-253.

Sternberger, L. A. (1974) Immunocytochemistry, Prentice-Hall, Englewood Cliffs, NJ.

Teitelman, G., T. H. Joh, and D. J. Reis (1978) Transient expression of a noradrenergic phenotype in cells of the rat embryonic gut. Brain Res. 158: 229-234.

Teitelman, G., M. D. Gershon, T. P. Rothman, T. H. Joh, and D. J. Reis (1981a) Proliferation and distribution of cells that transiently express a catecholaminergic phenotype during development in mice and rats. Dev. Biol. 86: 348-355.

Teitelman, G., T. H. Joh, and D. J. Reis (1981b) Transformation of catecholaminergic precursors into glucagon (A) cells in mouse embryonic pancreas. Proc. Natl. Acad. Sci. USA 78: 5225-5229.

Teitelman, G., T. H. Joh, and D. J. Reis (1981c) Linkage of the brainskin-gut axis: Islet cells originate from dopaminergic precursors. Peptides 2(Suppl. 2): 157-168.

Teitelman, G., T. H. Joh, L. Grayson, D. H. Park, D. J. Reis, and L. Iacovitti (1985) Cholinergic neurons of the chick ciliary ganglia express adrenergic traits in vivo and in vitro. J. Neurosci. 5: 29-39.

Ungerstedt, V. (1971) Stereotaxic mapping of the monoamine pathways in the rat brain. Acta Physiol. Scand. (Suppl.) 367: 1-48. 